\title{
Estimation of independent non-linear deformation modes for analysis of craniofacial malformations in crouzon mice
}

Hansen, Michael Sass; Olafsdóttir, Hildur; Darvann, Tron Andre; Hermann, Nuno V.; Oubel, Estanio; Larsen, Rasmus; Ersbøll, Bjarne Kjær; Frangi, Alejandro F.; Larsen, Per; Perlyn, Chad A.

Total number of authors:

14

Published in:

2007 IEEE International Symposium on Biomedical Imaging

Link to article, DOI:

10.1109/ISBI.2007.357097

Publication date:

2007

Document Version

Publisher's PDF, also known as Version of record

Link back to DTU Orbit

Citation (APA):

Hansen, M. S., Olafsdóttir, H., Darvann, T. A., Hermann, N. V., Oubel, E., Larsen, R., Ersbøll, B. K., Frangi, A. F., Larsen, P., Perlyn, C. A., Morris-Kay, G. M., Kreiborg, S., Wernick, M. (Ed.), \& Fessler, J. A. (Ed.) (2007). Estimation of independent non-linear deformation modes for analysis of craniofacial malformations in crouzon mice. In 2007 IEEE International Symposium on Biomedical Imaging IEEE.

https://doi.org/10.1109/ISBI.2007.357097

\section{General rights}

Copyright and moral rights for the publications made accessible in the public portal are retained by the authors and/or other copyright owners and it is a condition of accessing publications that users recognise and abide by the legal requirements associated with these rights.

- Users may download and print one copy of any publication from the public portal for the purpose of private study or research.

- You may not further distribute the material or use it for any profit-making activity or commercial gain

- You may freely distribute the URL identifying the publication in the public portal 


\title{
ESTIMATION OF INDEPENDENT NON-LINEAR DEFORMATION MODES FOR ANALYSIS OF CRANIOFACIAL MALFORMATIONS IN CROUZON MICE
}

\author{
Michael S. Hansen ${ }^{1}$, Hildur Ólafsdóttir ${ }^{1}$, Tron A. Darvann ${ }^{2}$, Nuno V. Hermann ${ }^{2,3}$, Estanislao Oubel ${ }^{4}$, Rasmus Larsen ${ }^{1}$, \\ Bjarne K. Ersbøll ${ }^{1}$, Alejandro F. Frangi ${ }^{4}$, Per Larsen ${ }^{2}$, Chad A. Perlyn ${ }^{5}$, Gillian M. Morriss-Kay ${ }^{6}$ and Sven Kreiborg ${ }^{2,3}$ \\ 1 IMM, Technical University of Denmark \\ 2 3D-Laboratory, University of Copenhagen, Denmark \\ ${ }^{3}$ School of Dentistry, University of Copenhagen, Denmark \\ ${ }^{4}$ Computational Imaging Lab, Department of Technology - D.326, Pompeu Fabra University, Barcelona, Spain \\ ${ }^{5}$ Washington University School of Medicine, St. Louis, MO, USA \\ ${ }^{6}$ Department of Physiology, Anatomy and Genetics, Oxford University, Oxford, UK
}

\begin{abstract}
Crouzon syndrome is a genetic disease resulting in premature fusion of cranial sutures and synchondroses causing craniosynostosis. A decade ago the Crouzon gene was discovered, and recently the first mouse model of the syndrome was generated. In this study, a set of Micro CT scannings of the heads of wild-type (normal) mice and Crouzon mice were investigated.

We present for what we believe is the first time, a statistical deformation model based on independent component analysis (ICA). A set of deformation parameters for each mouse was calculated using a B-spline-based nonrigid registration. From the parameters controlling the deformations for each subject, the statistical model was estimated.

ICA is demonstrated to provide localized deformation components, many of which give a clear separation between Crouzon and wild-type mice. This is a clear improvement of a previous principal component-based model, which only provided one global deformation component describing the disease. The ICA components allow interpretation of each deformation feature to be carried out independently of other features, and provides a basis for linking the observed craniofacial malformations to the fusing of sutures. ICA revealed an interesting new finding, not previously reported in the literature, namely asymmetries in the head in Crouzon mice. This phenomenon is probably caused by asymmetric closure of craniofacial sutures.
\end{abstract}

Index Terms - Statistical deformation model, independent component analysis, atlas, image registration

\section{INTRODUCTION}

Crouzon syndrome [1] is characterized by the premature fusion of the cranial sutures and synchondroses. This gives rise to craniofacial growth disturbances, which cause craniofacial malformations. To examine these deviations in detail, a genetic mouse model of the Crouzon syndrome has been created [2]. A detailed analysis of the craniofacial shape differences between Crouzon and wildtype mice was carried out by incorporating advanced imaging techniques, e.g. Micro CT . Studying the craniofacial shape differences in detail contributes to the understanding of the syndrome, surgery planning and diagnosis in humans.

A recent study, performing linear measurements on Micro CT scans, proved the mouse model applicable to reflect the craniofacial deviations occurring in humans with Crouzon syndrome [3]. Previously, we have extended this study to assess the local deformations between the groups by constructing a deformable shape and intensity-based atlas of wild-type (WT) mouse skulls. Deforming this atlas to all mice, the craniofacial shape differences can be analyzed [4]. To describe the differences intuitively and with fewer parameters, we built a statistical deformation model using principal components analysis (PCA). This model could not, however, localize the different traits in the different modes of variations [5]. This paper presents an improvement of the deformation model by applying independent component analysis (ICA) to the deformation fields. ICA has gained increasing popularity, and due to its inherent maximization of sparsity, it has previously been used for shape analysis, e.g. Hansen et al. [6]. To our knowledge this is the first time ICA has been applied to statistical analysis of a deformation model.

\section{DATA}

Production of Fgfr2 $2^{C 342 Y /+}$ and Fgfr2 ${ }^{C 342 Y / C 342 Y} \mathrm{mu}-$ tant mice (Crouzon mice) was previously described in [2]. All procedures were carried out in agreement with the United Kingdom Animals (Scientific Procedures) Act, guidelines of the Home Office, and regulations of the University of Oxford. Mutant mice of breeding age were determined by phenotype.

For three-dimensional (3D) CT scanning, $10 \mathrm{WT}$ and 
10 Fgfr2 ${ }^{\mathrm{C} 342 \mathrm{Y} /+}$ specimens at six weeks of age were sacrificed using Schedule I methods and fixed in 95\% ethanol. They were sealed and shipped to the Micro CT imaging facility at the University of Utah. Images of the skull were obtained at $46 \mu \mathrm{m} \times 46 \mu \mathrm{m} \times 46 \mu \mathrm{m}$ resolution using a GE Medical Systems EVS-RS9 Micro CT scanner.

\section{METHODS}

\subsection{Atlas building and Registration}

A craniofacial shape- and intensity-based atlas was constructed automatically from the Micro CT volumes of wild-type mice using a B-spline-based nonrigid registration [7]. The atlas was registered to each mouse in both groups using the same method [4]. To analyze the craniofacial shape differences between the two groups, the parameters of the nonrigid registration, i.e. the 160.000 control points of the B-splines, were analyzed using ICA.

\subsection{ICA on the deformation field}

The basic assumption of the ICA model used in the presented work, is a linear mixture model. The observed signal vector $X$ with $n$ dimensions, e.g. the observed 20 mice, is described as a vector of linear mixtures of $p$ independent source signals to be estimated, represented by the vector $S$. The mixture process, performed by the unknown mixing matrix $A_{n \times p}$ is governed by

$$
X=A S
$$

The FastICA algorithm was developed by Hyvärinen et al., and allows for a very efficient computation of the independent components [8].

The output $S$ is the independent deformation fields, and $A$ describes how the deformation fields were mixed to form the different mice. ICA has no inherent ordering of the components, but as we are interested in modes that separate Crouzon mice from wild-type mice, the Fisher discriminant was used as an ordering measure.

\section{RESULTS}

The accuracy of the image registration algorithm is essential for the deformation model to be valid. Using anatomical landmarks for validation the algorithm performed within inter-observer accuracy (as in [4]).

Our statistical analysis resulted in 8 modes of variation that distinguished between wild-type and Crouzon mice. Examples of pairwise scatter plots of these modes are shown in Figure 1.

It is evident that each mode separates the two groups to some degree. The modes 1, 2 and 8 share the feature that they only seem to describe variation in the Crouzon
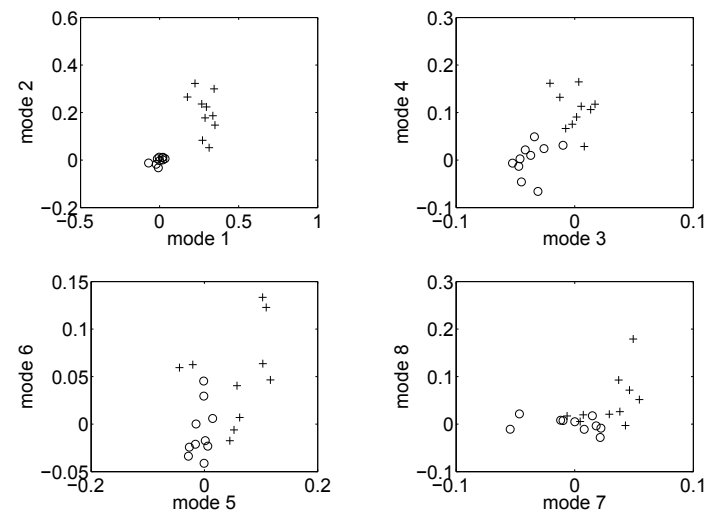

Fig. 1. Scatter plots of the 8 first independent modes. Wild-type mice are denoted by 'o' and Crouzon mice by '+'.
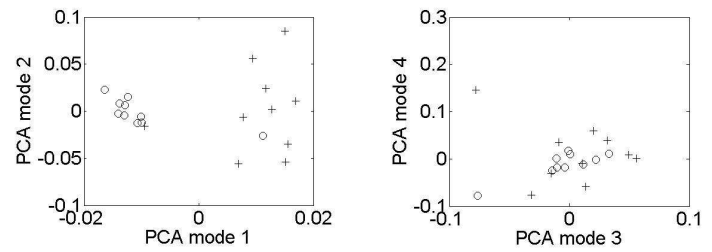

Fig. 2. Scatter plots of the 4 first PCA modes. Wildtype mice are denoted by 'o' and Crouzon mice by '+'.

mice, and not in the wild-type population. The other modes describe variation in both the wild-type and the diseased mice, but with greater variation for the Crouzon mice.

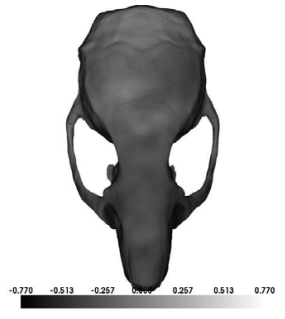

(a) 1st IC, wild-type mice

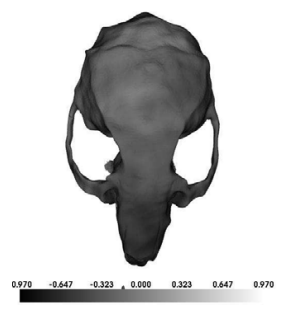

(b) 1st IC, Crouzon mice
Fig. 3. Deformations of the mouse atlas, the dorsal aspect of the skull. The colorbar indicates the local deformation in mm explained by the independent mode.

PCA applied to the deformation field describes global instead of local variation, as reported previously. In Figure 2 it is seen that PCA finds only one disease-status describing feature, i.e. component that separated WT mice from Crouzon mice [5]. ICA clearly estimates components that are strongly related to the disease status of the mice, most of the components also without ignoring 
the variation in the wild-type mice.

To assess the deformation described by each model visually, we segmented the bone structure of the deformation atlas, and show the variation observed in wildtype and in Crouzon mice, respectively. To facilitate the inspection the segmented surface was colored according to a greyscale where the intensity is determined by the deformation described by the mode (in $\mathrm{mm}$ ) of the skull at the specific point.

The first independent component (Figure 3) is seen to describe a strong deformation of the frontal region (nose and premaxilla), corresponding to a contraction and bending of this region. This variation was also observed as the first mode of variation in the PCA model, which was also the only describing mode of variation obtained with the PCA model [5].

The 4th component also shows a very interesting feature, observed in Figure 4. We see that the clivus and frontal regions are descending more in the Crouzon mice than in the wild-type mice, also noted as a brighter color because of high deformation of the fourth independent mode at these areas. This component in effect describes a bending of the cranial base, which according to Figure 1 is mainly seen in the Crouzon mice.

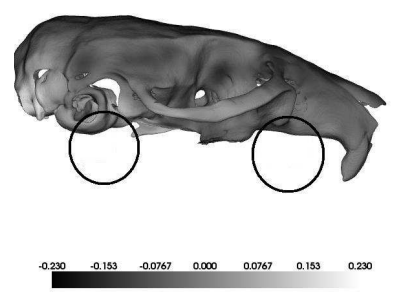

(a) 4th IC, wild-type mice

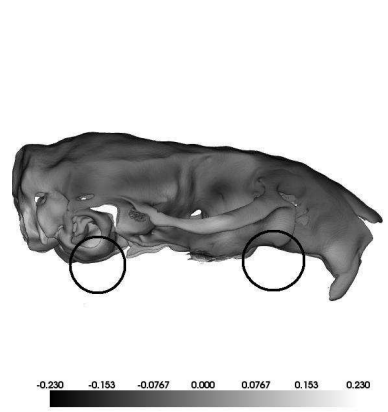

(c) 4th IC, Crouzon mice

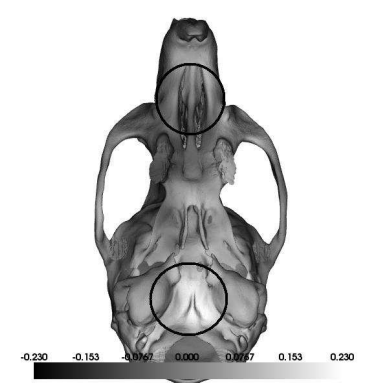

(b) 4th IC, wild-type mice

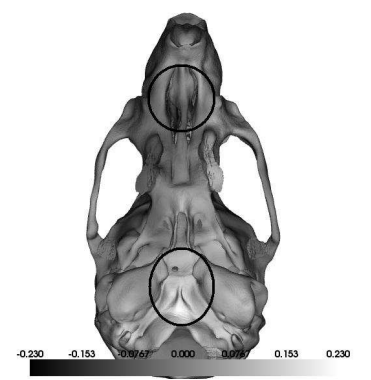

(d) 4th IC, Crouzon mice

Fig. 4. Deformations of the atlases described by the fourth independent component. Left: right lateral aspect of the skull. Right: the basal aspect of the skull.

The modes 2 and 8 also call for special attention since they are the only expressing asymmetric variation. The scatter plot in Figure 4 demonstrates that the score of both components are scattered closely around 0 for the, very close to symmetric, wild-type mice.

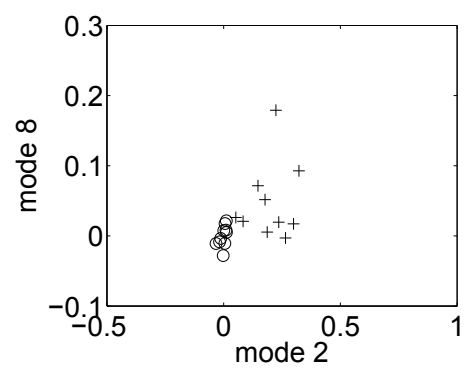

Fig. 5. Scatter plot of scores of the 2 nd and the 8 th independent components. 'o' denotes wild-type mice and '+' denotes Crouzon mice.

The two modes of variation are shown in a basal view in Figure 6. It is seen, from the intensity coding, that the major variation is found around the middle ear (tympanic bulla) and the upper jaw (maxilla and arcus zygomatic), but for the 2nd IC the variation is on the left side of the skull, and for the 8th IC the variation is on the right side. It appears that left and right tympanic bulla and the zygomatic arch vary in size on Crouzon mice independently in the left and the right side. Figure
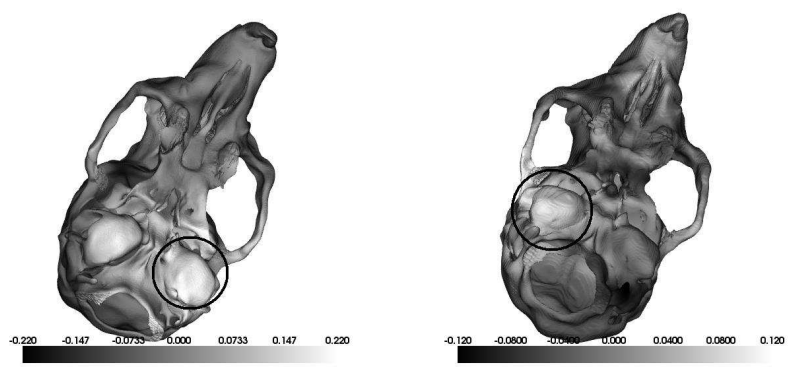

Fig. 6. Basal view of the skull shows deformations described by the 2 nd IC (left) and the 8 th IC (right). The colorbar indicates the local deformation in $\mathrm{mm}$.

7 gives a good view of the major variation explained by the two modes. The most important variation in both, is around the squamosal and in the shape of the middle ear. The squamosal of the Crouzon mouse appears deformed and it seems to affect the middle ear to be thinner, more skewed and with a more pointed shape than on the WT mouse. This is only on the deformed side. The correspondence between the two asymmetric modes is strong considering that the set of mice only contains 10 Crouzon mice. 


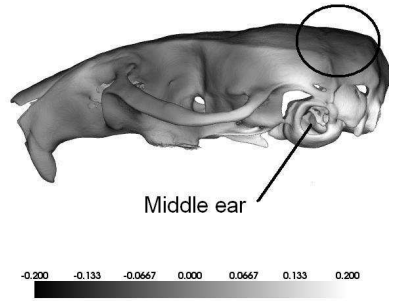

(a) 2nd IC, wild-type mice

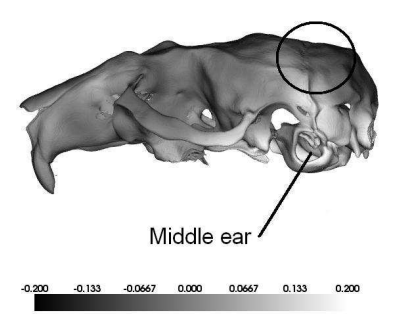

(c) 2nd IC, Crouzon mice

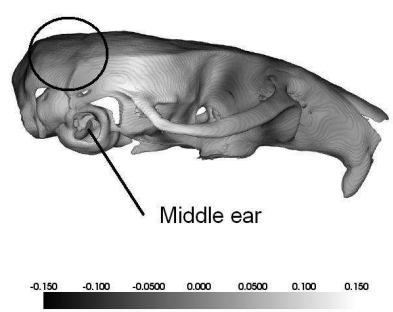

(b) 8th IC, wild-type mice

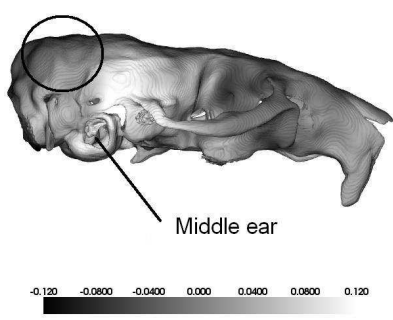

(d) 8th IC, Crouzon mice
Fig. 7. Deformations of the atlases described by the 2nd IC (left) and the 8th IC (right). Notice how the deformation of the middle ear appear similar in the two asymmetric ICs.

\section{CONCLUSION}

We have demonstrated the use of ICA as a powerful approach for statistical analysis of the deformation field obtained by nonrigid registration. Our initial hypothesis was that the shape of the head would differ significantly with large, individually distinct, local and global malformations, depending on how the different growth zones of the Crouzon mice fuse. The two ICA modes 1 and 4 showed global and very significant deformation, namely a contraction of the frontal region in the first mode and a angulation of the cranial base (probably caused by suture closure) in the 4 th mode. These variations were also observed in a previous study from a single concatenated mode of variation [4], but applying ICA we have learned that they are independent. The ICA modes 2 and 8 showed localized asymmetric variations around squamosal, the middle ear and the upper jaw, each mode describing variation on one side. This phenomenon is probably caused by asymmetric closure of the sutures in the region, but this needs to be investigated further in the future. Several localized components, separating normal mice from Crouzon mice, were encountered, increasing confidence that the craniofacial deformation model provides a good representation of the mice.

\section{ACKNOWLEDGEMENTS}

The Image Registration Toolkit was used under Licence from Ixico Ltd.

\section{REFERENCES}

[1] O. Crouzon, "Dysostose cranio-faciale héréditaire.," Bull Mem Soc Med Hop Paris, vol. 33, pp. 545-55, 1912.

[2] V. P. Eswarakumar, M. C. Horowitz, R. Locklin, G. M. Morriss-Kay, and P. Lonai, "A gain-of-function mutation of fgfr2c demonstrates the roles of this receptor variant in osteogenesis," Proc Natl Acad Sci, U.S.A., vol. 101, pp. 12555-60, 2004.

[3] C. A. Perlyn, V. B. DeLeon, C. Babbs, D. Govier, L. Burell, T. Darvann, S. Kreiborg, and G. MorrissKay, "The craniofacial phenotype of the Crouzon mouse: Analysis of a model for syndromic craniosynostosis using 3D MicroCT," Cleft Palate Craniofac. $J, 2006$.

[4] H. Ólafsdóttir, T. A. Darvann, N. V. Hermann, E. Oubel, B. K. Ersbøll, A. F. Frangi, Per Larsen, Chad A. Perlyn, G. Morriss-Kay, and S. Kreiborg, "Computational mouse atlases and their application to automatic assessment of craniofacial dysmorphology caused by Crouzon syndrome," Journal of Anatomy, 2007 (submitted).

[5] H. Ólafsdóttir, T. A. Darvann, B. K. Ersbøll, E. Oubel, N. V. Hermann, A. F. Frangi, P. Larsen, C. A. Perlyn, G. Morriss-Kay, and S. Kreiborg, "A craniofacial statistical deformation model of wildtype mice and Crouzon mice," in Symposium on Medical Imaging 200\%. feb 2007, The International Society for Optical Engineering (SPIE).

[6] M. S. Hansen, F. Zhao, H. Zhang, N. E. Walker, A. Wahle, T. Scholz, and M. Sonka, "Detection of connective tissue disorder from 3D MR images using independent component analysis," CVAMIA, pp. 13-24, 2006.

[7] D. Rueckert, L. I. Sonoda, C. Hayes, D. L. G. Hill, M. O. Leach, and D. J. Hawkes, "Nonrigid registration using free-form deformations: application to breast MR images," IEEE Transactions on Medical Imaging, vol. 18, no. 8, pp. 712-21, 1999.

[8] A Hyvärinen, "Fast and robust fixed-point algorithms for independent component analysis," IEEE Transactions on Neural Networks, vol. 10, no. 3, pp. 626-634, 1999. 